\title{
Organ Measurements Directionality
}

National Cancer Institute

\section{Source}

National Cancer Institute. Organ Measurements Directionality. NCI Thesaurus. Code

C119883.

A qualifier for the direction on the body the org an measurement is performed. 